\begin{tabular}{c} 
Volume and Issues Obtainable at Center for Sustainability Research and Consultancy \\
Journal of Business and Social Review in Emerging Economies \\
ISSN: 2519-089X \& ISSN (E): 2519-0326 \\
Volume 7: Issue 4 December 2021 \\
CSRᄃ \\
Journal homepage: www.publishing.globalcsrc.org/jbsee \\
\hline
\end{tabular}

\title{
Normative Reference Standard for Handgrip Strength among Adolescent Students in South Punjab Pakistan: A Cross-Sectional Study
}

*Syed Muhammad Zeeshan Haider Hamdani, Lecturer, Faculty of Arts \& Social Sciences, Department of Sports Sciences, Bahauddin Zakariya University, Multan, Pakistan

Jie Zhuang, Professor, Faculty of Sport Science, School of Kinesiology, Shanghai University of Sport, Shanghai, China

Wang Tian, Scholar, Faculty of Sport Science, School of Kinesiology, Shanghai University of Sport, Shanghai, China

Syed Ghufran Hadier, Ph.D. Scholar, School of Physical Education, Shanxi University, China

*Corresponding author's email: syedhamdaniphd@gmail.com

\begin{tabular}{l} 
ARTICLE DETAILS \\
\hline History \\
Revised format: Nov 2021 \\
Available Online: Dec 2021
\end{tabular}

Keywords

Sports Sciences,

Human Health,

Muscular Strength,

Normative Reference Standard,

Percentile Curves.

JEL Classification

L83, Z2

\begin{abstract}
Purpose: The study provided the age and gender-specific normative standard by using LMS technique and comparison with international reference values for the muscular strength by hand grip among adolescents of South Punjab, Pakistan.

Design/Methodology/Approach: A cross sectional descriptive research design was adopted, 60 public high school with 2970 students aged 12-16 contributed. Hand grip strength was measured using (GRIPX Digital Hand Dynamometer). LMS method was used for calculating reference norms. Age and gender-specific smoothed percentile curves P5th to P95th were acquired for hand grip strength.

Findings: The results revealed that the boys were higher in muscular strength than their counterparts, South Punjab's adolescents were found lower in strength than the compared adolescents. Around $40 \%$ of the population is falling in the poor and very poor zone.

Implications/Originality/Value: The current study presented the foremost age and gender specific hand grip strength percentile curves and provided the health benefit zones for the adolescent of South Punjab.
\end{abstract}

(C) 2021 The authors, under a Creative Commons AttributionNonCommercial 4.0

Recommended citation: Hamdani, S. M. Z. H., Khan, Zhuang, J., Tian, W. \& Haider, S. G. (2021). Normative Reference Standard for Handgrip Strength among Adolescent Students in South Punjab Pakistan: A Cross-Sectional Study. Journal of Business and Social Review in Emerging Economies, 7 (4), 997-1009.

\section{Introduction}

Grasping or throwing is an ability of humans which is based on the strength of the hand (Khan et al., 2019). The hand grip strength which is considered as the most commonly used as well as 
least invasive measure to predict the overall muscular strength and is usually used to gauge the strength and fitness of a person. Hand grip strength is useful in assessing the hand functions of person (Jawaria, 2018). Hand grip strength is an indicator that specifically tells us about the strength of the upper extremity and predicts the overall muscular strength too. Muscle strength is an indicator that depicts the health especially in youth population (Ekelund et al., 2007) and work as an independent risk factor when it comes to mortality rate of adults (Garcia-Hermoso et al., 2018). There are many techniques available for measuring the overall physical fitness and muscular strength, but they require intensive and long duration procedures. On the other hand, hand grip strength test is valid, reliable and feasible to measure muscular strength of body with a single dynamometer instrument.

Grip strength has a core importance in clinical studies. there are several clinical outcomes such as cardiovascular diseases and its related mortality that is linked to be predicted health related risk by hand grip strength (McGrath et al., 2020). Not only this but also a sequential decrease in handgrip strength is a predictor of stroke. However, handgrip strength cannot be used to determine the cardiovascular functions (Fredriksen et al., 2018). It is observed that cardiac patients have a decrease in muscle strength and in turn decreased handgrip strength. Hand grip strength of the dominant hand is found less in cardiac patients when compared with normal individuals of the same age (Mirza et al., 2020). Thus handgrip strength demonstrates starring role in determining the health status of any individual as well (Musalek et al., 2017).

Obesity has become dangerous phenomena and created emergency situation in modern era. Almost every country whether it is developed or developing country are facing the pandemic of obesity especially at younger population. Individuals having BMI greater than 25 have increased risk of developing various diseases. hand grip strength is now considered as a valid indicator of accelerating aging process in humans because obese persons have high cortisol (aging hormone) that cause them to have a low muscle strength and that is indicated by a decrease in hand grip strength (Mirza et al., 2020). Physical activity has been found a resistance against obesity and in prevention of several other diseases (Lavie et al., 2019). There is an important correspondence between level of physical activity as well as BMI with the hand grip strength of adolescents that has been stated in studies (Mirza et al., 2020, Tahir et al., 2021). Physical activity has a positive effect in increasing hand grip strength and effect of BMI on hand grip strength too (Mirza et al., 2020, Tahir et al., 2021, Rafique et al., 2014).

Age specific and gender specific reference values have already been published globally (Catley, 2013, Peterson, 2015). However, a large amount of handgrip publications is found in the USA, Europe, Australia other Asian country like China and Korea and other pacific or more in developed countries (Perna et al., 2016, Laurson et al., 2017, Cohen et al., 2010, Catley, 2013, Sun et al., 2020, Lee et al., 2017). In contrast, there is scarcity of reference values of handgrip strength as well as other fitness components indicators into developing or below developing countries, which makes impossible to evaluate the health or fitness indexes especially at young aged adolescents (Ruiz et al., 2008). That is why the normative percentile values of hand grip strength have been worked as a framework for the classification of fitness levels for adolescents. Less than 20th centile is "very low/poor"; from $20^{\text {th }}$ to $40^{\text {th }}$ centiles as "low/poor"; from $40^{\text {th }}$ to $60^{\text {th }}$ centiles as "moderate"; from $60^{\text {th }}$ to $80^{\text {th }}$ centiles as "high/good"; and when it is above the $80^{\text {th }}$ centile, it is "very high/good" (Catley, 2013, Tomkinson et al., 2018). It is stated that if level of physical fitness is below the fifth centile then there is an increases risk of development of CVD in future times (Twisk et al., 2002).

From the perspective of public health and construction of reference values of handgrip strength to identify the levels of adolescent's handgrip strength, hand grip strength dynamometer is found to be inexpensive, portable and reliable instrument. WHO has diverted its attention towards this 
growing issue and is encouraging to increase the level of physical activity and physical fitness to have a good muscular strength and hand grip strength is the best measure to assess (Fühner et al., 2020). This marks the importance of hand grip strength. But to dismay, Pakistan is one of the countries where this direst domain is highly neglected. There is no even single research done on 12 to 16 years old adolescents of South Punjab, Pakistan. Therefore, it became the prime focus of study to know the normative value of hand grip strength in this region and also compared the current calculated reference values with published international studies.

Physical fitness in early age plays an important role in the health and fitness of adolescents as well as in adulthood. Developed as well as developing countries are keeping eye strictly on adolescents' fitness as this age group is really important in the term of physical and mental development of individual. Physical fitness criteria have already been studied globally especially for adolescents to minimize the high rate of obesity which has become a leading phenomenon of the modern era. The importance of defining a normative value lies the fact that it helps in assessing the current status and making the comparison among the diverse age and gender specific populations of different countries but no such effort has been made in South Punjab Pakistan. Current study had on two objectives firstly, construction of age-gender-specific normative reference values of hand grip strength by using LMS technique for the adolescents of south Punjab Pakistan. Lastly, it compared the hand grip strength with the other published reference values of hand grip strength and developed health benefit zone followed by normative cut off values similar to the USA, European and Asian studies for the adolescent population of South Punjab (Perna et al., 2016, Laurson et al., 2017, Cohen et al., 2010, Catley, 2013, Sun et al., 2020, Lee, 2017). This was the first study in South Punjab Pakistan which presented the handgrip strength normative reference values by using LMS technique (Cole, 1990).

\section{Methods}

It is a Cross-sectional study. Sampling was done by Stratified random Sampling. The main Strata is South Punjab which has further divided into three administrative division as Stratum and three most populous district (Multan, Bahawalpur, D. G. Khan) were selected for study representation. Randomly selected sixty (12\% of high schools from three districts of South Punjab, Pakistan) public high schools were included for data collection according to Education Department official statistics (Punjab Government School Information System, 2020). Sixty schools were further distributed equally among the three stratum as Multan 20 (33.33\%), Bahawalpur 20 (33.33\%) and D. G. Khan 20 (33.33\%). For the determination of sample size current study opted the equation used by Suresh et al., 2012 for the sample size calculation (Suresh et al., 2012). Consequential, the sample aged 12-16, total of 3012 school adolescents were selected randomly out of which 50\% were boys and 50\% were girls from the South Punjab Pakistan. Initially, a total of 3012 participant's measurements were obtained however, forty one participants were excluded from Sample due to outliers. Inclusion criteria for participants was that student should be physically and mentally fit. The exclusion criteria was based on the report of any type of dysfunction that can limit the physical activity e.g. any disease or physical or mental disability.

\section{Ethical Approval and Consent}

Trained research assistants from Bahauddin Zakariya University, South Punjab, Pakistan were assistants for data collection under the supervision of senior member of the team. The consent was taken and hence the participants were allowed to withdraw any time from study. For that written approval for holding this research was achieved by education authorities and school Principal. Verbal consent from guardian and students were taken. The study was conducted according to ethical standards in sport and exercise science research (Harriss, et al., 2019). The study was approved by the research ethical board of faculty of sport science, school of kinesiology, Shanghai University of Sport (SUS), Shanghai, China. 


\section{Procedure}

\section{Anthropometric Parameters}

Age (years), gender, height, weight, and BMI (kg/m2) etc. were measured and saved. These anthropometric measurements were taken when students were barefoot as well as wearing a light cloth. A portable electronic scale was used for the measurement of body mass. The status of Body mass was classified using the Centre of disease control (CDC) age specific and genderspecific thresholds (CDC, 2017).

\section{Handgrip Strength}

A standard adjustable digital dynamometer (GRIPX Digital Hand Dynamometer) was used for the measurement of handgrip. A brief demonstration was given to students and verbal instructions were also provided to explain the test, and if there was a need, the students were helped in adjusting it to their hand size as was decided by our predetermined protocols (CDC, 2017).

The dynamometer was calibrated by us according to the already known body masses in a periodic manner and there was no drift observed. Handgrip strength was observed in the subject when he was in a standing position with the shoulder in an adducted position and was neutrally rotated as well as the arms being parallel but not in touch with the body interface. The students were asked to squeeze the handle for a maximum of three to five seconds. There was no verbal encouragement allowed during the test time. There was a two trials period allowed for each of the limb. The cumulative average was calculated for every peak grip strength $(\mathrm{kg})$ that was recorded and that average was then applied. So, the values of hand grip which we are demonstrating in this study are as a result of combination of the values of left hand as well as and right-handed subjects. The results were observed irrespective of the dominance of left or right hand. The handgrip strength recorded the peak grip strength $(\mathrm{kg})(\mathrm{CDC}, 2017)$.

\section{Data Analysis}

After raw data acquisition, unique identification codes were assigned to every individual, as for the area status and the gender (Male $=1$ and Female $=2$ ). Data was entered in the sheet of Microsoft excel. The Current study adopted a cut-off of SD- score (Z-Score) and this study agreed \pm 5 Z-scores cut-off points to identify outliers. Finally, a sample of 2970 (approximately 98\%) participants was subjected for further statistical analysis. Descriptive and inferential analysis, percentages $(\%)$, frequencies, Mean, and standard deviation of variables were analyzed. To check the normality of data (Kolmogorov-Smirnov test) was also applied. The mean differences of gender-wise and which were calculated via a non-parametric Mann-Whitney U test Chi-square test was also applied to know the association of age-gender with indicators. The LMS method was used and L ( $\gamma$ lambda), M $(\mu)$ and $S\left({ }^{\delta}\right.$ sigma) curves were made to obtain the percentile value of muscular strength indicator of health related physical fitness (Cole, 1990). In this regard, LMS method was adopted and generated in R statistical software version 3.0.2. descriptive and inferential analysis Statistical Package for the Social Sciences (SPSS) version 21.0. The value of $P<0.05$ was set as a significant.

\section{Results}

Table 1 Demographic analysis age and gender specific

\begin{tabular}{cccc}
\hline Indicators & Boys & Girls & Total \\
\hline Age-groups (years) & & & \\
$12 \mathrm{~N}(\%)$ & $291(19.7 \%)$ & $299(20.24 \%)$ & $590(19.9 \%)$ \\
$13 \mathrm{~N}(\%)$ & $295(19.97 \%)$ & $298(20.17 \%)$ & $593(20.0 \%)$ \\
$14 \mathrm{~N}(\%)$ & $298(20.17 \%)$ & $296(20.04 \%)$ & $594(20.0 \%)$ \\
$15 \mathrm{~N}(\%)$ & $298(20.17 \%)$ & $300(20.31 \%)$ & $598(20.1 \%)$ \\
$16 \mathrm{~N}(\%)$ & $295(19.7 \%)$ & $300(20.31 \%)$ & $595(20.0 \%)$ \\
Area & & &
\end{tabular}




$\begin{array}{cccc}\text { Multan N (\%) } & 495(33.51 \%) & 498(33.71 \%) & 993(33.4 \%) \\ \text { D G Khan N (\%) } & 491(33.24 \%) & 498(33.71 \%) & 989(33.3 \%) \\ \text { Bahawalpur N (\%) } & 491(33.24 \%) & 497(33.64 \%) & 988(33.3 \%) \\ \text { Total } & 1477(100 \%) & 1493(100 \%) & 2970(100 \%)\end{array}$

Note: The data was presented as $\mathrm{N}$ : Number of sample and percentage $\%$.

Sample population distribution for each age category is presented in Table 1 . There is equal participation from each group in a category whether it is age related, gender based or area wise.

Table 2 Gender Specific Anthropometric Component of Participants

\begin{tabular}{|c|c|c|c|c|c|c|c|}
\hline \multirow{2}{*}{ Component } & \multicolumn{2}{|r|}{ Total } & \multicolumn{2}{|r|}{ Boys } & \multicolumn{2}{|r|}{ Girls } & \multirow{2}{*}{$P$-value } \\
\hline & $\mathrm{N}$ & $\mathrm{M} \pm \mathrm{SD}$ & $\mathrm{N}$ & $\mathrm{M} \pm \mathrm{SD}$ & $\mathrm{N}$ & $\mathrm{M} \pm \mathrm{SD}$ & \\
\hline Age (years) & 2970 & $14.01 \pm 1.41$ & 1477 & $14.01 \pm 1.41$ & 1493 & $14.00 \pm 1.41$ & $<0.001$ \\
\hline Height $(\mathrm{cm})$ & 2970 & $159.53 \pm 10.51$ & 1477 & $160.50 \pm 11.50$ & 1493 & $158.57 \pm 9.34$ & $<0.001$ \\
\hline Weight (kg) & 2970 & $43.00 \pm 9.10$ & 1477 & $45.02 \pm 9.78$ & 1493 & $41.00 \pm 7.89$ & $<0.001$ \\
\hline BMI $\left(\mathrm{kg} / \mathrm{m}^{2}\right)$ & 2970 & $16.80 \pm 2.67$ & 1477 & $17.30 \pm 2.41$ & 1493 & $16.29 \pm 2.82$ & $<0.001$ \\
\hline HGS (kg) & 2970 & $24.39 \pm 13.36$ & 1477 & $31.81 \pm 14.85$ & 1493 & $17.06 \pm 5.39$ & $<0.001$ \\
\hline
\end{tabular}

Note: The data was presented as mean \pm standard deviation, HGS (kg): Hand Grip Strength (kilograms)

Table 2 shows mean age of boys and girls was $14.01 \pm 1.41$ years $(\mathrm{P}<0.001)$. The average height of the population was $159.53 \pm 10.51 \mathrm{~cm}(\mathrm{P}<0.001)$. The average weight of boys and girls was

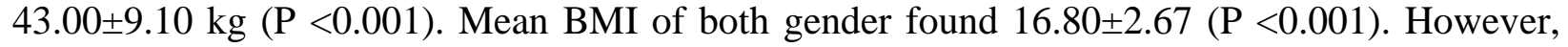
mean anthropometric variables, i.e., height, weight, BMI were higher in boys than in girls. While talking about handgrip strength results showed that $24.39 \pm 13.36 \mathrm{~kg}$ ( $\mathrm{P}<0.001)$ averagely. Whereas results reflected that boys handgrip strength was found almost doubled than girls as $31.81 \pm 14.85 \mathrm{~kg}$ than $17.06 \pm 5.39 \mathrm{~kg}$ respectively.

Table 3 Hand Grip (kg) Percentile by Age and Gender in Adolescents Aged 12-16 from South Punjab

\begin{tabular}{|c|c|c|c|c|c|c|c|c|c|}
\hline Age & $\mathrm{N}$ & $\mathrm{M}$ & P 5 & P 20 & P 40 & P 50 & P 60 & P 80 & P 95 \\
\hline \multicolumn{10}{|l|}{ Boys } \\
\hline 12 & 291 & 22.53 & 9.38 & 14.64 & 19.83 & 22.53 & 25.50 & 33.36 & 46.77 \\
\hline 13 & 295 & 25.77 & 12.67 & 17.85 & 23.03 & 25.77 & 28.83 & 37.21 & 52.50 \\
\hline 14 & 298 & 29.00 & 15.78 & 20.99 & 26.21 & 29.00 & 32.15 & 40.97 & 57.92 \\
\hline 15 & 298 & 32.24 & 18.69 & 24.02 & 29.37 & 32.24 & 35.50 & 44.70 & 62.96 \\
\hline 16 & 295 & 35.47 & 21.30 & 26.89 & 32.48 & 35.47 & 38.86 & 48.49 & 67.72 \\
\hline \multicolumn{10}{|l|}{ Girls } \\
\hline 12 & 299 & 14.12 & 8.30 & 11.05 & 13.12 & 14.12 & 15.17 & 17.77 & 21.77 \\
\hline 13 & 298 & 15.01 & 8.49 & 11.27 & 13.80 & 15.01 & 16.28 & 19.36 & 24.00 \\
\hline 14 & 296 & 16.48 & 8.65 & 12.10 & 15.09 & 16.48 & 17.92 & 21.36 & 26.36 \\
\hline 15 & 300 & 18.16 & 9.90 & 13.76 & 16.79 & 18.16 & 19.55 & 22.80 & 27.32 \\
\hline 16 & 300 & 20.18 & 10.78 & 15.30 & 18.68 & 20.18 & 21.68 & 25.11 & 29.75 \\
\hline
\end{tabular}

Note: N, Number of participants; M, median 

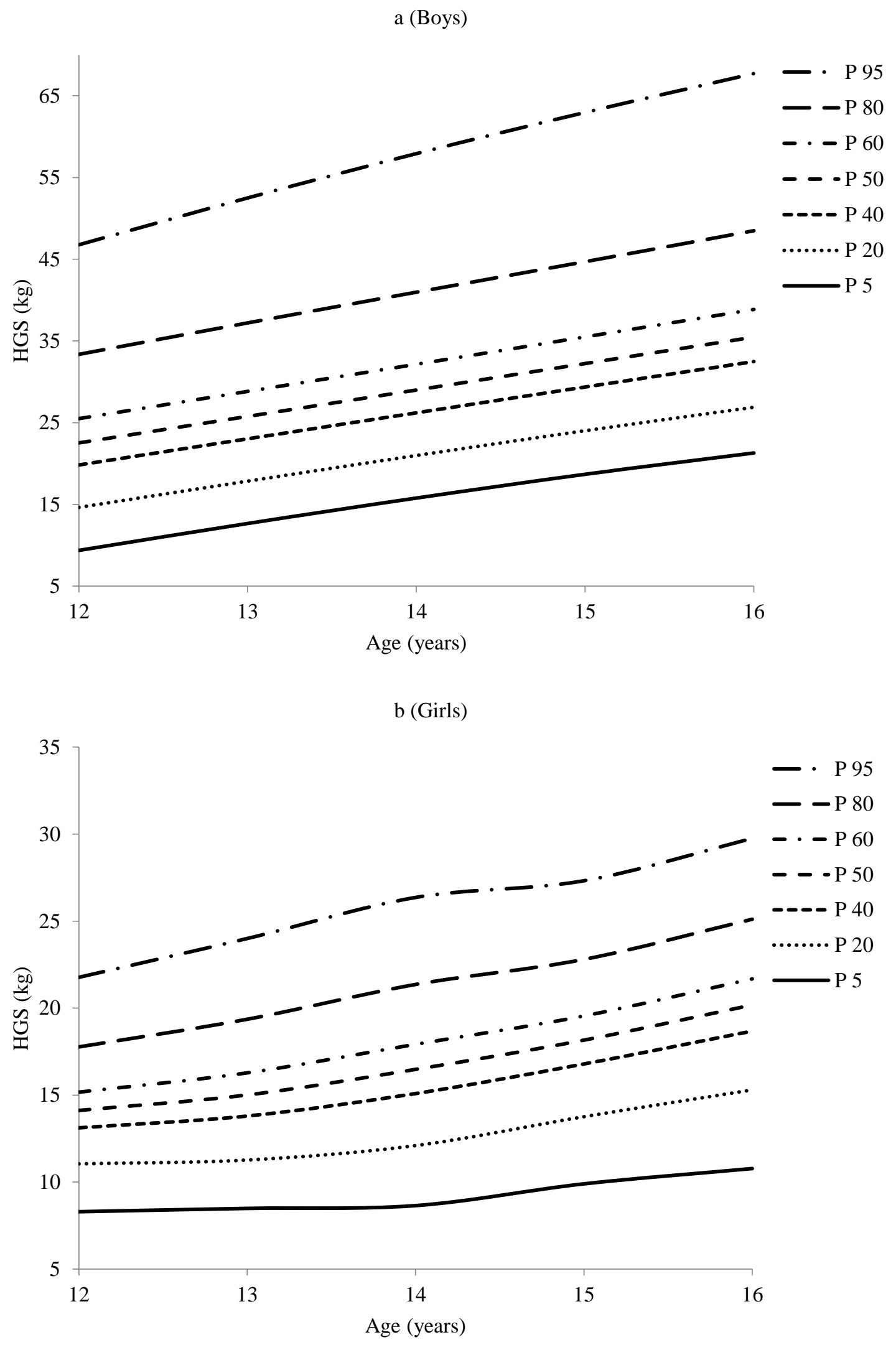

Figure 1 Hand grip strength (kg) percentile curve for the South Punjab.

The Smoothed LMS curves (for the $5^{\text {th }}, 20^{\text {th }}, 40^{\text {th }}, 50^{\text {th }}, 60^{\text {th }}, 80^{\text {th }}$ and $95^{\text {th }}$ centiles) for the handgrip strength of boys and girls are presented in figure 1 and corresponding numeric are presented in table 3 and figure 1. It is noticeable from the centiles that the boys of every age showed a better hand grip strength test than girls. For boys and girls, the value of $50^{\text {th }}$ centile of 
handgrip strength was ranging from 22.53 to $35.47 \mathrm{~kg}$ and 13.12 to $20.18 \mathrm{~kg}$ respectively. Moreover, it was observed that there was approximately 3 to $5 \mathrm{~kg}$ average annual increase was detected in boys and girls. In both boys as well as girls, it was observed that the muscle strength increased across the age range, however the increase in performance was observed to be marked between 14 and 15 years.
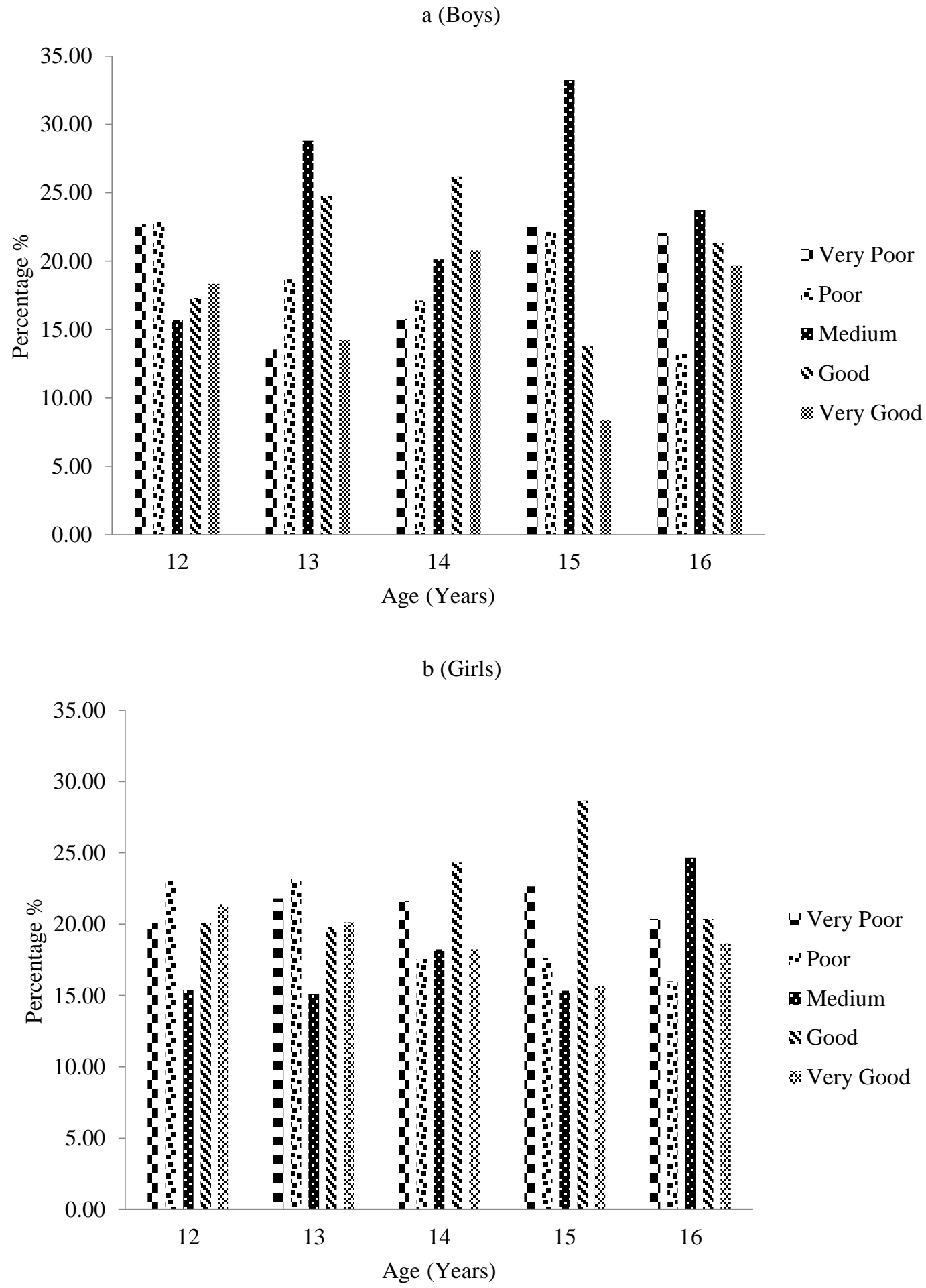

Figure 2 Percent of Adolescents by hand Grip Strength Health benefit zone by age and Gender. Figure 2 presented that boys at aged 12 and girls at aged 15 had same maximum percentage as $22.67 \%$ in very poor category respectively. The maximum percentage of the medium category population was found at ages of $15(33.22 \%)$ and 16 years $(24.67 \%)$ between boys and girls respectively. In very good category boys at age 14 and girls at age 12 as well as 13 had almost 
identical percentages as $21 \%$. Thus, boys seemed better than girls in good and very good category muscular strength, but both the boys and girls need to work hard for the improvement in their muscular strength as well as overall healthy life.

\section{Comparison with foreign normative references}

Table 4 Hand Grip (kg) Comparison of P50 between present studies and other published studies

\begin{tabular}{ccccccc}
\hline $\begin{array}{c}\text { Age } \\
\text { (years) }\end{array}$ & $\begin{array}{c}\text { Present } \\
\text { Study }\end{array}$ & $\begin{array}{c}\text { Laurson et al., } \\
(2017)\end{array}$ & $\begin{array}{c}\text { Sun et al., } \\
(2020)\end{array}$ & $\begin{array}{c}\text { Catley et al., } \\
(2013)\end{array}$ & $\begin{array}{c}\text { Ramírez et } \\
\text { al.,(2017) }\end{array}$ & $\begin{array}{c}\text { Lee, S. } \\
(2017)\end{array}$ \\
\hline Boys & & & & & & \\
12 & 22.5 & 22.6 & 23.9 & 22.7 & 17.5 & - \\
13 & 25.8 & 28.4 & 27.8 & 25.8 & 21.1 & 24.8 \\
14 & 29.0 & 34.6 & 31.7 & 30.7 & 23.8 & 29.5 \\
15 & 32.2 & 39.5 & 35.3 & 36.5 & 28.5 & 33.2 \\
16 & 35.5 & 42.9 & 38.3 & - & 31.1 & 36.0 \\
Girls & & & & & & \\
12 & 14.1 & 20.6 & 19.9 & 21.4 & 18.1 & - \\
13 & 15.0 & 24.6 & 21.6 & 23.6 & 19.5 & 20.4 \\
14 & 16.5 & 27.1 & 23.7 & 25.4 & 21.9 & 21.6 \\
15 & 18.2 & 28 & 24.5 & 26.9 & 21.5 & 22.2 \\
16 & 20.9 & 28.2 & 25.8 & - & 22.7 & 22.3 \\
\hline
\end{tabular}

Note: - Not reported

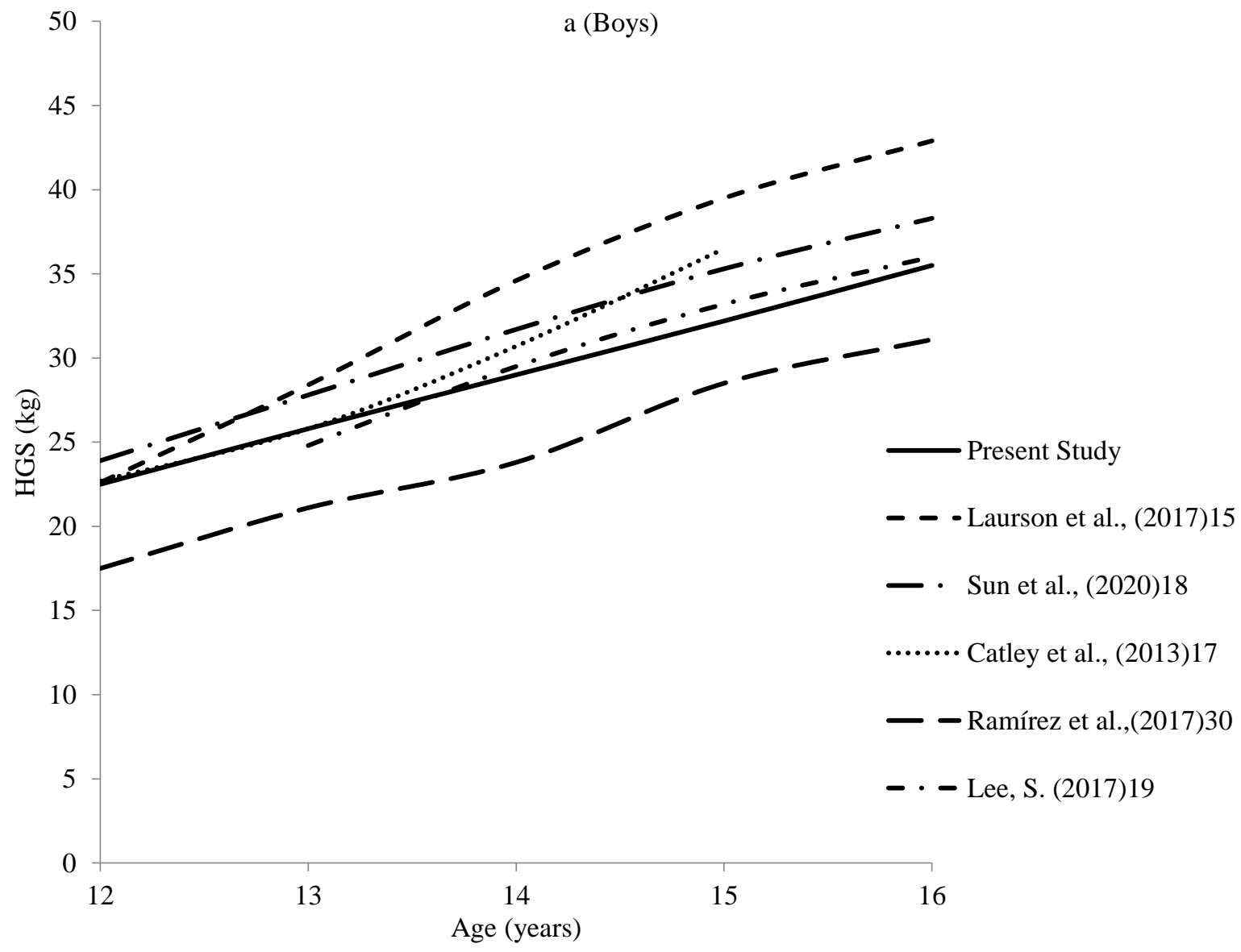




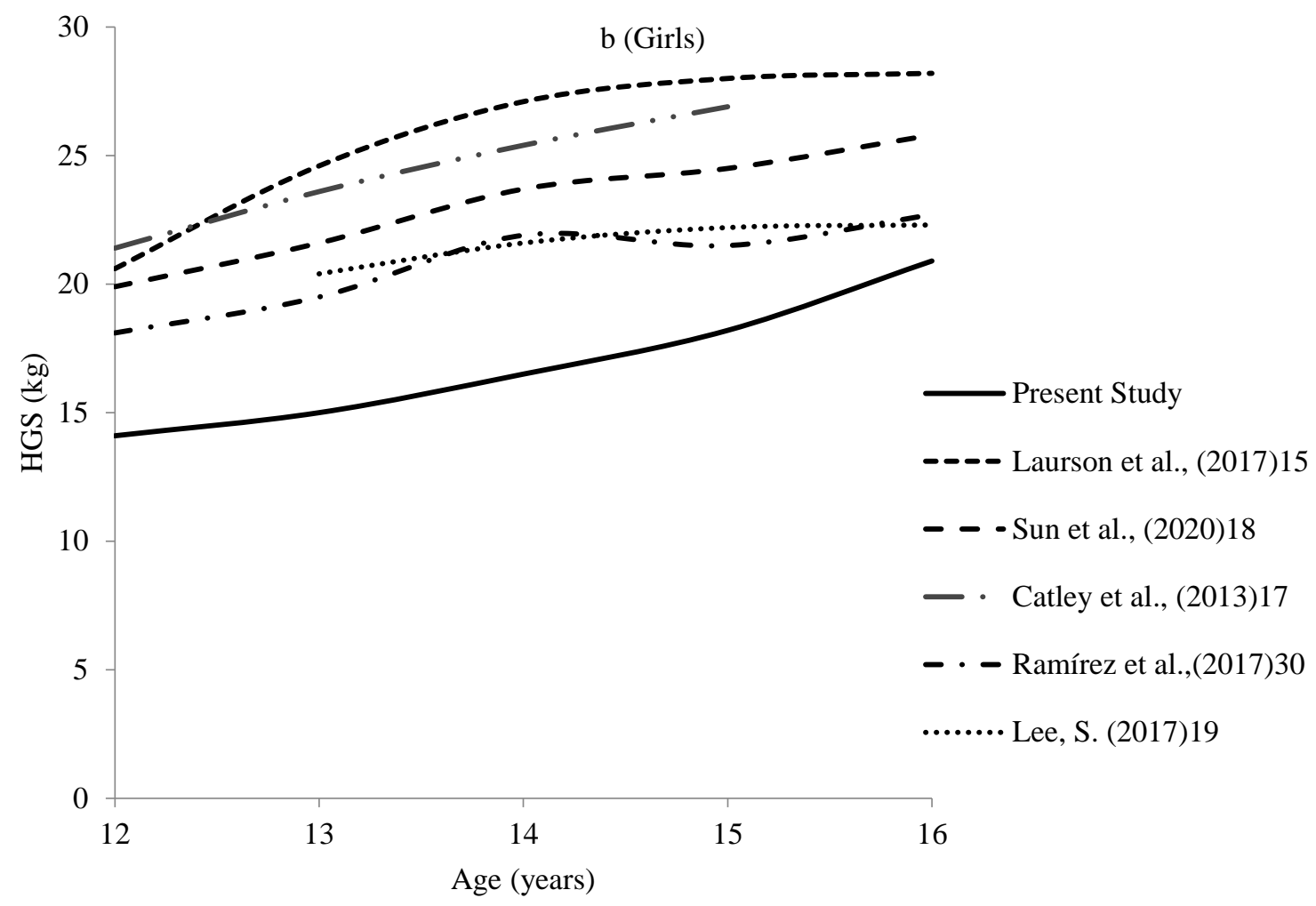

Figure 3 HGS (kg) Comparison of P50th between Present Studies and Published Studies

Table 4 and figure 3 shows the normative reference values (the value of 50th centile) of handgrip strength that was also measured in $(\mathrm{kg})$ referenced from different studies with respect to age and gender. The European, Australian, Chinese, Colombian and Korean adolescents showed a score that is comparatively better than Pakistani adolescents according to $50^{\text {th }}$ centile values, except for Colombian boys at all given years of age (Laurson et al., 2017, Catley, 2013, Sun et al., 2020, Ramírez-Vélez et al., 2015, Lee et al., 2017). In contrast, Pakistani male children scored higher than their Colombian counterparts. However, Colombian girls scored higher hand grip strength than Pakistani girls of all ages stated. Muscular strength of south Punjab Pakistan's Adolescence is found higher in boys than girls. Moreover, Muscular strength of Pakistani Adolescence on basis of age and gender is lower than the most of other nations.

\section{Discussion}

Anthropometric measures are important while discussing handgrip strength. Because Anthropometric measures like height weight and BMI are important indicators of hand grip strength as stated in a Korean study (Lee et al., 2017). Moreover, anthropometric characteristics can help in selection and application of appropriate sports training design as well as exercises for the rehabilitation and treatment of people having poor hand grip strength or other hand related deformities. Current study presented all the mean anthropometric variables, i.e., height, weight, BMI were higher in boys than in girls and the same was observed in similar study of Pakistani population where the anthropometric measures were higher in boys than girls (Tahir et al., 2021).

Meanwhile, the mean of the handgrip strengths of south Punjab Pakistan's adolescents was marked among boys than girls. A study also concluded that value of the mean of the handgrip strength was significantly marked in boys than girls (Jawaria, 2018). A research study conducted in city of Karachi, Pakistan concluded that the muscle strength as well as hand grip strength was low in females as compared to males (Mirza et al., 2020). A study of Pakistani population in as well as Columbian are also in congruence and also showed that hand grip strength in females is lower than males, this also demonstrates that low females have low muscle strength as compared 
to males regardless of age specification (Jawaria, 2018, Ramírez-Vélez et al., 2015). These sex related differences are evident in many other studies as well (Laurson et al., 2017, Cohen et al., 2010, Ramírez-Vélez et al., 2015). The average value of hand grip strength in current study is $31.81 \pm 14.85 \mathrm{~kg}$ while, another Pakistani study's hand grip strength outcome was $30.75 \pm 14.35$ $\mathrm{kg}$ which is in congruence with the current findings (Mirza et al., 2020).

Current study also made comparison of the values of $\mathrm{P}^{\text {th }}{ }^{\text {th }}$ percentile of South Punjab's

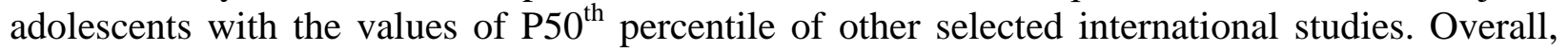
European, Australian, Chinese, Colombian and Korean adolescents showed scores were more marked than Pakistani children at the 50th centile (Laurson et al., 2017, Catley, 2013, Sun et al., 2020, Lee et al., 2017, Ramírez-Vélez et al., 2015). In contrast, Pakistani children of male sex scored higher than their Colombian counterparts. However, Colombian girls also scored higher than Pakistani girls of all ages stated. Another comparison study showed a comparison of the values of the hand grip strength of the student of Tsinghua University Beijing and University of Sindh Pakistan, that showed hand grip strength of female Chinese students was higher than female Pakistani students (Rafique et al., 2014). Our results are in congruence with another Pakistani study that also concluded that hand grip strength of Pakistani adolescents is less than consolidated values by $30.8 \%$ in males and $24.1 \%$ in females (Jawaria, 2018). The reason for the difference with respect to the age and gender is usually interpreted by individual differences for instance physical differences, difference in muscle mass, total body weight, and stature (Sherriff et al., 2008). Moreover data from a recent study in Pakistan depicted an overall increase in screen time among youth, which might be accounted for low levels of handgrip strength as literature supports that low physical activity and high sedentary behaviour may affect the strength of an individual (Ijaz et al., 2020).

Results of Columbian adolescent's hand grip strength revealed that more percentage of boys and girls of 12 to 16 years of age were in the category of "Need improvement" and another study conducted in USA reported that a significant number of 12 to 16 years old boys were found in "Need improvement" zone than girls as the current study also confirmed these findings after having the similar results (Ramírez-Vélez et al., 2015). More percentage of girls were in the excellent category of health benefits zone in this study which was based on Columbine adolescent of age 12 to 16 years as similar to current study which also reflects that the adolescent girls of 12 to 16 years old were found more in numbers than boys in good or excellent category (Ramírez-Vélez et al., 2015). Hence, these research findings are also verifying our result and hence strengthening the results of our study.

Current study successfully calculated the normative reference values of hand grip strength of adolescents of south Punjab Pakistan by using LMS method. Additionally, also provided the health benefit zone for adolescents to better understand their current level to make further improvement of muscular strength as well as overall fitness.

Physical educators are requested to monitor and form policies to escalate vigorous physical activity levels among youth. Thus milestone can be achieved by increasing sports at school and club organizations (Pozuelo-Carrascosa et al., 2018). So the schools are acknowledged as potential setting to improve healthy lifestyle among children and adolescents (Escalante et al., 2011).

\section{Conclusion}

Current study provided the age and gender specific anthropometric measurements and BMI of adolescents of South Punjab, Pakistan's boys were found having higher values of BMI. Moreover, hand grip strength was higher in male at each percentile level and age group than girls. This demonstrated boys had higher muscular strength with respect to each age group than 
girls. The comparison with international standards showed that hand grip strength of Pakistani children is lower than many other countries including China, USA, Europe and Australia. As hand grip strength is considered as a marker of muscular strength indicator of health related physical fitness, so this is creating an alarming situation for Pakistani adolescents. The government as well as responsible institutions should focus more on the promotion of physical activity, and healthy life style in adolescents at schools specifically.

\section{References}

Catley, M. J., \& Tomkinson, G. R. (2013). Normative health-related fitness values for children: analysis of 85347 test results on 9-17-year-old Australians since 1985. British journal of sports medicine, 47(2), 98-108.

CDC. (2017). Anthropometry Procedures Manual. United States: CDC. Retrieved 12 14, 2021,From;https://www.cdc.gov/nchs/data/nhanes/nhanes_11_12/Muscle_Strength_Proc Manual.pdf

Cohen, D. D., Voss, C., Taylor, M. J. D., Stasinopoulos, D. M., Delextrat, A., \& Sandercock, G. R. H. (2010). Handgrip strength in English schoolchildren. Acta Paediatrica, 99(7), 1065-1072.https://doi.org/10.1111/j.1651-2227.2010.01723.x

Cole, T. J. (1990). The LMS method for constructing normalized growth standards. European journal of clinical nutrition, 44(1), 45-60. PMID: 2354692.

Ekelund, U., Anderssen, S. A., Froberg, K., Sardinha, L. B., Andersen, L. B., \& Brage, S. (2007). Independent associations of physical activity and cardiorespiratory fitness with metabolic risk factors in children: the European youth heart study. Diabetologia, 50(9), 1832-1840. https://doi.org/10.1007/s00125-007-0762-5

Escalante, Y., Backx, K., Saavedra, J. M., García-Hermoso, A., \& Dominguez, A. M. (2011). Relationship between daily physical activity, recess physical activity, age and sex in scholar of primary school, Spain. Revista española de salud pública, 85, 481-489.

Fredriksen, P. M., Mamen, A., Hjelle, O. P., \& Lindberg, M. (2018). Handgrip strength in 6-12year-old children: The Health Oriented Pedagogical Project (HOPP). Scandinavian journal of public health, 46(21_suppl), 54-60. https://doi.org/10.1177/1403494818769851

Fühner, T., Kliegl, R., Arntz, F., Kriemler, S., \& Granacher, U. (2020). An update on secular trends in physical fitness of children and adolescents from 1972 to 2015: A systematic review. Sports Medicine, 1-18. https://doi.org/10.1007/s40279-020-01373-X

García-Hermoso, A., Cavero-Redondo, I., Ramírez-Vélez, R., Ruiz, J. R., Ortega, F. B., Lee, D. C., \& Martínez-Vizcaíno, V. (2018). Muscular strength as a predictor of all-cause mortality in an apparently healthy population: a systematic review and meta-analysis of data from approximately 2 million men and women. Archives of physical medicine and rehabilitation, 99(10), 2100-2113. https://doi.org/10.1016/j.apmr.2018.01.008

Harriss, D. J., MacSween, A., \& Atkinson, G. (2019). Ethical Standards in Sport and Exercise Science Research: 2020 Update. International journal of sports medicine, 40(13), 813817. https://doi.org/10.1055/a-1015-3123

Ijaz, S., Ismail, S., Fayyaz, L., Ashraf, A., Razzaq, Y., \& Chaudhry, M. A. (2020). Physical Activity, Screen Time and Emotional Wellbeing of Population during COVID-19 Pandemic in Pakistan. Biomedica, 36(4). https://doi.org/10.51441/BioMedica/5-77.

Jawaria, S. (2018). Evaluation of Pakistani adult handgrip strength reference values through dynamometer. Journal of Pakistan Orthopaedic Association, 29(04), 139-144.

Khan, H. A., Junaid, K., Jamshaid, I., Khaliq, M. A., Khan, H. S., Ahmad, M., \& Hasan, S. (2019). Effect of recreational sports on handgrip strength and anthropometry in adolescent basketball and volleyball players. Pakistan Journal of Physiology, 15(1), 3740. http://pjp.pps.org.pk/index.php/PJP/article/view/910

Laurson, K. R., Saint-Maurice, P. F., Welk, G. J., \& Eisenmann, J. C. (2017). Reference curves for field tests of musculoskeletal fitness in US children and adolescents: The 2012 
NHANES National Youth Fitness Survey. The Journal of Strength \& Conditioning Research, 31(8), 2075-2082. https://doi.org/10.1519/JSC.0000000000001678

Lavie, C. J., Carbone, S., Kachur, S., O'keefe, E. L., \& Elagizi, A. (2019). Effects of physical activity, exercise, and fitness on obesity-related morbidity and mortality. Current sports medicine reports, 18(8), 292-298. https://doi.org/10.1249/JSR.0000000000000623

Lee, S., Ko, B. G., \& Park, S. (2017). Physical Fitness Levels in Korean Adolescents: The National Fitness Award Project. Journal of obesity \& metabolic syndrome, 26(1), 61-70. https://doi.org/10.7570/jomes.2017.26.1.61

McGrath, R., Johnson, N., Klawitter, L., Mahoney, S., Trautman, K., Carlson, C., Rockstad, E., \& Hackney, K. J. (2020). What are the association patterns between handgrip strength and adverse health conditions? A topical review. SAGE open medicine, 8, 2050312120910358. https://doi.org/10.1177/2050312120910358

Mirza, F., Fazal, A., Shabbir, K., Farooq, H., \& Ahmed, S. (2020). Association of Grip Strength with obesity cortisol; Possible indicators of biological ageing. International Journal Of Endorsing Health Science Research (IJEHSR), 8(3), 145-152. https://doi.org/10.29052/IJEHSR.V8.I3.2020.145-152

Musalek, C., \& Kirchengast, S. (2017). Grip Strength as an Indicator of Health-Related Quality of Life in Old Age-A Pilot Study. International Journal of Environmental Research and Public Health, 14(12), 1447. https://doi.org/10.3390/ijerph14121447

Perna, F. M., Coa, K., Troiano, R. P., Lawman, H. G., Wang, C. Y., Li, Y., Moser, R. P., Ciccolo, J. T., Comstock, B. A., \& Kraemer, W. J. (2016). Muscular Grip Strength Estimates of the U.S. Population from the National Health and Nutrition Examination Survey 2011-2012. Journal of strength and conditioning research, 30(3), 867-874. https://doi.org/10.1519/JSC.0000000000001104

Peterson, M. D., \& Krishnan, C. (2015). Growth charts for muscular strength capacity with quantile regression. American journal of preventive medicine, 49(6), 935-938. https://doi.org/10.1016/j.amepre.2015.05.013

Pozuelo-Carrascosa, D. P., García-Hermoso, A., Álvarez-Bueno, C., Sánchez-López, M., \& Martinez-Vizcaino, V. (2018). Effectiveness of school-based physical activity programmes on cardiorespiratory fitness in children: a meta-analysis of randomised controlled trials. British journal of sports medicine, 52(19), 1234-1240. https://doi.org /10.1136/bjsports-2017-097600.

Punjab Governemnt. (2020, 1 25). sis.punjab.gov.pk. Retrieved from: https://sis.punjab.gov.pk/dashboard\#enrollment

Rafique, M., Bing, Z., Ansari, M. A., Soomro, J. A., \& Wei, S. Z. (2014). Comparing BMI and hand grip strength of Tsinghua University Beijing and University of Sindh Pakistan students. J of management infor, 4(1), 36-44.

Ramírez-Vélez, R., Rodrigues-Bezerra, D., Correa-Bautista, J. E., Izquierdo, M., \& Lobelo, F. (2015). Reliability of health-related physical fitness tests among Colombian children and adolescents: the FUPRECOL study. PloS one, 10(10), e0140875. https://doi.org/10.1371/journal.pone.0140875

Ruiz, J. R., Sui, X., Lobelo, F., Morrow, J. R., Jackson, A. W., Sjöström, M., \& Blair, S. N. (2008). Association between muscular strength and mortality in men: prospective cohort study. Bmj, 337. doi: https://doi.org/10.1136/bmj.a439

Sherriff, A., Wright, C., Reilly, J., McColl, J., Ness, A., \& Emmett, P. (2008). Age- and sexstandardised lean and fat indices derived from bioelectrical impedance analysis for ages 7-11 years: Functional associations with cardio-respiratory fitness and grip strength. British Journal of Nutrition, 101(12), 1753-1760. https://doi.org/10.1017/S0007114508135814

Sun, Y., Yin, X., Li, Y., Bi, C., Li, M., Yang, X., ... Zhang, F. (2020). Normative Values for Muscular Fitness for Chinese Children and Adolescents Aged 7-18 Years. Sustainability, 12(15), 6078. https://doi.org/10.3390/su12156078 
Suresh, K., \& Chandrashekara, S. (2012). Sample size estimation and power analysis for clinical research studies. Journal of human reproductive sciences, 5(1), 7-13. https://doi.org/10.4103/0974-1208.97779

Tahir, R., Rauf, F. A., Ismail, S., Khan, H. S., \& Hasan, S. (2021). Association between handgrip strength and maximum expiratory flow with site-specific bone mineral density of healthy young adults. JPMA. The Journal of the Pakistan Medical Association, 71(1(A)), 178182. https://doi.org/10.47391/JPMA.682

Tomkinson, G. R., Carver, K. D., Atkinson, F., Daniell, N. D., Lewis, L. K., Fitzgerald, J. S., \& Ortega, F. B. (2018). European normative values for physical fitness in children and adolescents aged 9-17 years: results from 2779165 Eurofit performances representing 30 countries. British Journal of Sports Medicine, 52(22), 1445-1456. https://doi.org/10.1136/bjsports-2017-098253.

Twisk, J. W. R., Kemper, H. C. G., \& Van Mechelen, W. (2002). Prediction of cardiovascular disease risk factors later in life by physical activity and physical fitness in youth: general comments and conclusions. International journal of sports medicine, 23(S1), 44-50. https://doi.org/10.1055/s-2002-28461 